\title{
Correlation between sequence divergence and polymorphism reveals similar evolutionary mechanisms acting across multiple timescales in a rapidly evolving plastid genome
}

\author{
Karen B Barnard-Kubow ${ }^{1 *}$, Daniel B Sloan ${ }^{2}$ and Laura F Galloway ${ }^{1}$
}

\begin{abstract}
Background: Although the plastid genome is highly conserved across most angiosperms, multiple lineages have increased rates of structural rearrangement and nucleotide substitution. These lineages exhibit an excess of nonsynonymous substitutions (i.e., elevated $\mathrm{dN} / \mathrm{dS}$ ratios) in similar subsets of plastid genes, suggesting that similar mechanisms may be leading to relaxed and/or positive selection on these genes. However, little is known regarding whether these mechanisms continue to shape sequence diversity at the intraspecific level.

Results: We examined patterns of interspecific divergence and intraspecific polymorphism in the plastid genome of Campanulastrum americanum, and across plastid genes found a significant correlation between $\mathrm{dN} / \mathrm{dS}$ and pN/ pS (i.e., the within-species equivalent of $d N / d S$ ). A number of genes including ycf1, ycf2, clpP, and ribosomal protein genes exhibited high $\mathrm{dN} / \mathrm{dS}$ ratios. McDonald-Kreitman tests detected little evidence for positive selection acting on these genes, likely due to the presence of substantial intraspecific divergence.

Conclusions: These results suggest that mechanisms leading to increased nucleotide substitution rates in the plastid genome are continuing to act at the intraspecific level. Accelerated plastid genome evolution may increase the likelihood of intraspecific cytonuclear genetic incompatibilities, and thereby contribute to the early stages of the speciation process.
\end{abstract}

Keywords: Plastid, Selection, dN/dS, pN/pS, Reproductive isolation, Intraspecific, Chloroplast, Sequence evolution

\section{Background}

The structure of the plastid genome is generally conserved across the angiosperms [1], and its nucleotide substitution rates are usually low relative to the nuclear genome [2]. However, multiple lineages exhibit extensively rearranged plastid genomes as well as increased rates of nucleotide substitution and elevated $\mathrm{dN} / \mathrm{dS}$ ratios for some genes [3]. While this connection suggests the potential for a common underlying cause of structural instability and increased nucleotide substitution rates [3], it is important to note that while structural instability impacts the plastid genome as whole, the increase in substitution

\footnotetext{
* Correspondence: kbb7sh@virginia.edu

'Department of Biology, University of Virginia, P.O. Box 400328,

Charlottesville, VA 22904-4328, USA

Full list of author information is available at the end of the article
}

rate appears to vary depending on gene function [4]. In lineages that show increased substitution rates, similar sets of plastid genes have experienced increased substitution rates and elevated $\mathrm{dN} / \mathrm{dS}$ ratios, suggesting the possibility of common mechanisms or selective regimes acting on these genes in independent angiosperm groups. However, it remains unclear whether these patterns reflect positive selection, relaxed purifying selection, changes in underlying mutation rates, a breakdown in DNA repair mechanisms such as gene conversion [5], or some combination of these.

Accelerated evolution in the plastid genome of some angiosperm lineages raises the question as to whether the mechanisms responsible continue to operate at the intraspecific level. Numerous studies examining nucleotide substitution rates and potential signatures of selection 
in the plastid genome, based on variation in $\mathrm{dN} / \mathrm{dS}$, have been carried out based on divergence among species $[4,6-10]$, but data describing genome-wide intraspecific sequence variation are needed to investigate whether accelerated plastid genome evolution is occurring within species. Estimates of intraspecific polymorphism are also useful for interpreting interspecific divergence, as it allows for distinguishing between the effects of positive selection and relaxed purifying selection on nucleotide substitution rates based on changes in the relative ratio of non-synonymous to synonymous changes before and after selection has acted [11,12]. Accordingly, positive selection is expected to lead to a significantly higher ratio for interspecific divergence than for intraspecific polymorphism.

We examined patterns of sequence divergence and polymorphism in Campanulastrum americanum to determine whether similar mechanisms of plastid genome evolution are acting within as well as between species. This species is a good study system in which to address these questions as it is in the Campanulaceae, a family in which the taxa have highly rearranged plastid genomes $[13,14]$, increasing the likelihood of detecting intraspecific accelerated plastid evolution. In particular we sought to answer the following questions. 1) Do a similar set of plastid genes exhibit increased nucleotide substitution rates and elevated $\mathrm{dN} / \mathrm{dS}$ ratios in C. americanum as found in previous studies with other species? 2) Are similar patterns found when examining plastid sequence variation among populations within $C$. americanum? 3 ) Do we find evidence for positive selection leading to increased substitution rates and elevated $\mathrm{dN} / \mathrm{dS}$ ratios in these plastid genes?

\section{Methods}

\section{Study system}

Campanulastrum americanum is a monocarpic herb found in the eastern half of the United States. Individuals are autotetraploid, annual or biennial, and primarily outcrossing $[15,16]$. The Campanulaceae has been shown to have highly rearranged plastid genomes as well as the potential for biparental plastid inheritance $[17,18]$. Crossing studies in C. americanum have found that while inheritance is primarily maternal, biparental and paternal inheritance occurs in roughly $25 \%$ of offspring (Barnard-Kubow, unpublished results). However, plastid polymorphism within populations appears relatively low, with genotyping at five loci (including portions of ycf1, rps2, and rps4) finding individuals within a population to be generally fixed for plastid haplotype (Barnard-Kubow, unpublished results). Therefore, while biparental inheritance may complicate full assembly of the plastid genome when using a maternal family, it is unlikely to cause significant error in terms of estimates of polymorphism or in determining the presence/ absence of plastid genes.

\section{Sample material and library construction}

For sequencing the plastid genome of C. americanum, 180 grams of fresh leaf tissue was collected from multiple individuals from a single maternal family (i.e., seeds from a single plant) from a population in Virginia (Table 1). Individuals were germinated in a growth chamber from field-collected seed and grown for several months in the greenhouse with regular watering and fertilization.

For examining within species polymorphism of the plastid genome, 150 grams of fresh leaf tissue was collected and pooled from multiple individuals from four populations of $C$. americanum (VA, MN, OH, and $\mathrm{AL}$ ), including the same VA population used for the single population plastid sequencing (Table 1). These populations were chosen because they span the geographic range of $C$. americanum and were known to differ genetically based on sequencing of individual chloroplast loci (Barnard-Kubow et al., unpublished results). VA individuals were transplanted from the field, while $\mathrm{MN}, \mathrm{OH}$, and $\mathrm{AL}$ individuals were germinated from field-collected seed in a growth chamber. Plants from all four populations were then grown for several months in the greenhouse with regular watering and fertilization. Intact chloroplasts were isolated from the single population (VA) and pooled samples using a combination of differential centrifugation and separation on a sucrose step gradient $[19,20]$. Chloroplasts were then lysed, and DNA was obtained via a phenolchloroform extraction and ethanol precipitation. The purity of plastid DNA (cpDNA) was confirmed by restriction digestion.

For each plastid sample, shotgun libraries were constructed with multiplex identifier (MID) tags following standard protocols for sequencing on a Roche 454 GSFLX platform with Titanium reagents. MID-tagged libraries were sequenced as part of a larger pooled sample. All 454 library construction and sequencing steps were performed at the Genomics Core Facility in the University of Virginia's Department of Biology. A total of 28,694 and 24,552 sequencing reads were obtained from the VA and pooled libraries, respectively.

Table 1 Location information for the populations used in this study

\begin{tabular}{lll}
\hline Population & Latitude & Longitude \\
\hline VA (Virginia, USA) & 37.35495 & -80.55415 \\
AL (Alabama, USA) & 34.65048 & -86.51643 \\
MN (Minnesota, USA) & 44.81650 & -93.30758 \\
OH (Ohio, USA) & 41.11472 & -81.51806 \\
\hline
\end{tabular}


The mean sequence lengths were $335 \mathrm{bp}$ for the VA library and $339 \mathrm{bp}$ for the pooled library. The reads from each library were deposited in NCBI's Short Read Archive [SRX595708 and SRX595709].

\section{Plastid assembly and annotation}

454 reads for the single population sample were assembled using Roche's GS de novo Assembler v2.3 ("Newbler") using default settings. Initial assembly produced hundred of contigs, however many of these were identified as bacterial or nuclear contamination. By visualizing the remaining contigs in Consed v21 [21] and using information regarding reads that span multiple contigs, 63 of the initial contigs were reassembled into nine final contigs with a total length of $147.3 \mathrm{~kb}$ and an average single copy coverage depth of $20 \times$. For the $\operatorname{ccs} A$ gene, PCR and Sanger sequencing were used to obtain sequence spanning a gap and complete the full sequence.

DOGMA [22] was used to annotate the protein, transfer RNA (tRNA), and ribosomal RNA (rRNA) genes for each of the contigs. One gene, clpP, exhibited high sequence divergence in the first exon. To determine the full sequence of the gene, correctly identify the exon/intron boundaries, and confirm transcription of the gene, $c l p P$ was amplified from cDNA constructed from an individual from the same VA population. Another gene, $y c f 1$, also exhibited high sequence divergence and appeared to have multiple frameshift mutations. However, these frameshift mutations were in long homopolymer or repetitive regions, raising the possibility they were due to 454 sequencing errors. PCR and Sanger sequencing confirmed that the frameshifts were the result of homopolymer-related sequencing errors. The corrected sequence yielded an intact $y c f 1$ reading frame. The final annotated contig sequences were deposited to GenBank under accession [GenBank:KJ920499-KJ920507].

\section{Interspecific divergence in cpDNA sequence}

To estimate divergence and $\mathrm{dN} / \mathrm{dS}$ ratios for plastid coding genes, the following species were used as outgroups and the corresponding gene sequences were obtained from GenBank: Trachelium caeruleum in the Campanulaceae [GenBank:NC_010442], and two more distantly related species, Helianthus annuus [GenBank: NC_007977] and Nicotiana tabacum [GenBank:NC_001879]. Outgroups were chosen to span a range of phylogenetic distances with one, T. caeruleum, in the Campanulaceae, and another, $H$. annuus, in the Asterales. Sequences were aligned with MUSCLE [23] as implemented in Codon Code Aligner v3.5 (CodonCode Corporation). High sequence divergence was observed for both $y c f 1$ and $y c f 2$, necessitating the deletion of large regions of unalignable sequence. An average of 28 regions were removed per outgroup, with deletions averaging $78 \mathrm{bp}$ and ranging up to $465 \mathrm{bp}$. Therefore, the resulting divergence values for these genes are underestimated. For clpP, the T. caeruleum sequence was re-annotated using DOGMA to locate the gene in the full chloroplast sequence obtained from GenBank and using homology between C. americanum, $H$. annuus, and $N$. tabacum to designate the intron/ exon boundaries (Additional file 1). Gene alignments were deposited in Dryad [24].

The relative rates of sequence divergence and $\mathrm{dN} / \mathrm{dS}$ ratio were determined for the protein coding genes using codon-based models of evolution in PAML v4.4 [25]. All analyses implemented a constrained topology with $T$. caeruleum and C. americanum monophyletic relative to $H$. annuus and N. tabacum, as T. caeruleum and $C$. americanum are within the same family. Codon frequencies were determined by an F3 $\times 4$ model. The parameter values for $\mathrm{dN} / \mathrm{dS}$ and transition/transversion ratio were estimated from the data with initial values of 0.4 and 2 respectively. Separate $\mathrm{dN} / \mathrm{dS}$ values were estimated for each branch. Analyses were run on separate concatenations for each of the following sets of protein genes: 1) ATP synthase $(a t p), 2)$ NADH-plastoquinone oxidoreductase $(n d h), 3)$ cytochrome b6/f complex (pet), 4) photosystem I $(p s a), 5)$ photosystem II $(p s b), 6)$ large ribosomal subunit $(r p l), 7)$ small ribosomal subunit $(r p s)$, and 8) RNA polymerase (rpo), as well as the following individual protein genes: $c c s A, c e m A, c l p P$, matK, $r b c L$, $y c f 1, y c f 2, y c f 3$, and $y c f 4$. See Additional file 2: Table S1 for a list of specific genes included in each concatenation. The $p s b T$ gene was excluded from the analysis because it was multicopy in C. americanum, and pet $N$ was excluded because the $T$. caeruleum copy was unalignable. PAML estimated a dS value of zero for $c l p P$ on the terminal branch for $C$. americanum, resulting in an undefined $\mathrm{dN} / \mathrm{dS}$ ratio. For subsequent analyses we estimated $\mathrm{dS}$ and $\mathrm{dN} / \mathrm{dS}$ for clpP assuming a single synonymous substitution. All PAML files used were deposited in Dryad [24].

We tested for signatures of positive selection (defined by a $\mathrm{dN} / \mathrm{dS}$ value significantly greater than one) by constraining the $\mathrm{dN} / \mathrm{dS}$ ratio to one for the terminal branch leading to $C$. americanum for any genes where this branch had an initial estimated $\mathrm{dN} / \mathrm{dS}$ ratio greater than one. Separate $\mathrm{dN} / \mathrm{dS}$ values were estimated for each of the remaining branches. Likelihood ratio tests were used to compare the constrained and unconstrained analyses and determine if the estimated $\mathrm{dN} / \mathrm{dS}$ ratios were significantly greater than one [26]. We applied a Bonferroni correction factor of 17 to account for multiple comparisons (17 genes/concatenations). To further examine sequence divergence and the potential for positive selection in one gene that showed a high $\mathrm{dN} / \mathrm{dS}$ ratio, clpP, maximum likelihood trees were constructed for $\operatorname{clp} P$ intronic and exonic sequence separately using Arabidopsis thaliana 
as an outgroup. Trees were constructed using baseml in PAML v4.4 [25] with a fixed topology and a GTR model of evolution based on results from jModelTest v2.1.5 $[27,28]$.

\section{Intraspecific polymorphism in cpDNA sequence}

To identify within species polymorphism and estimate $\mathrm{pN} / \mathrm{pS}$ (within species equivalent of $\mathrm{dN} / \mathrm{dS}$ ), 454 reads from the pooled multiple-population $C$. americanum sample were mapped to the assembled contigs from the VA sample using Roche's GS Reference Mapper v2.5.3. The mapped reads had an average single copy coverage depth of $25 \times$. A Perl script was written to use annotated gene locations and SNP information from the "HCDiff" mapping file to extract all high-confidence SNPs and identify them as genic/intergenic, exonic/intronic, and non-synonymous/synonymous (Additional file 3). Total numbers of non-synonymous and synonymous SNPs were tallied for each set of concatenated or individual genes, using the same concatenation groupings as used when estimating $\mathrm{dN} / \mathrm{dS}$. To estimate $\mathrm{pN}, \mathrm{pS}$, and the $\mathrm{pN} / \mathrm{pS}$ ratio, the nonsynonymous and synonymous polymorphism counts were divided by the number of nonsynonymous and synonymous sites determined by PAML in our $\mathrm{dN} / \mathrm{dS}$ analyses.

\section{Polymorphism and divergence}

We determined whether similar sets of genes have an elevated $\mathrm{dN} / \mathrm{dS}$ and $\mathrm{pN} / \mathrm{pS}$ ratio by running a correlation analysis on the $\log$ transformed $\mathrm{dN} / \mathrm{dS}$ and $\mathrm{pN} / \mathrm{pS}$ ratios from each gene or concatenation (PROC CORR, SAS 9.3, SAS Institute, INC. 2011). Only genes or concatenations that had three or more SNPs were included in the correlation analysis $(\mathrm{n}=11)$.

Additionally, to test whether genes with elevated $\mathrm{dN} / \mathrm{dS}$ ratios have been under positive selection versus relaxed purifying selection, McDonald-Kreitman (M-K) tests [12] were run using Fisher's exact test for each set of concatenated or individual genes (PROC FREQ, SAS 9.3, SAS Institute, INC. 2011). Pairwise divergence data between $C$. americanum and each of the three outgroup species ( $T$. caeruleum, $H$. annuus, and $N$. tabacum) were obtained using a Perl script to extract all pairwise SNPs from the four species gene alignments used in the plastid divergence analysis above (Additional file 4). We applied a Bonferroni correction factor of 51 to account for multiple comparisons (17 genes/concatenations $\times 3$ outgroup species).

\section{Results}

\section{Plastid genome assembly}

Sequencing of purified cpDNA from $C$. americanum produced high depth coverage of the plastid genome, which was assembled into nine contigs, totaling $147.3 \mathrm{~kb}$.
A complete assembly of $C$. americanum's plastid genome was unattainable due to the presence of a large number of repetitive regions. These findings fit with those from the plastid genome of $T$. caeruleum, another member of the Campanulaceae, which also contains an unusually high level of repeats [29]. The plastid genomes of the Campanulaceae family have also been found to contain many inversions $[13,14,29]$. Likely this propensity for structural instability explains why mapping $C$. americanum reads to T. caeruleum's plastid genome was not helpful in further assembly of $C$. americanum's plastid genome. The potential for biparental inheritance of the plastid genome and subsequent heteroplasmy may have further contributed to difficulties in assembly when using a single maternal family.

Several genes commonly found in other angiosperms appear to be missing or presumed non-functional in $C$. americanum. No evidence was found for $a c c D$, even when searching against the raw reads, while infA is likely a pseudogene due to multiple internal stop codons. Only a $50 \mathrm{bp}$ fragment remains of $r p l 23$, though this fragment is present in at least two locations. The rps16 intron has also been lost. These three genes and the rps16 intron have also been lost or are presumed non-functional in T. caeruleum [29], suggesting these losses occurred prior to the divergence of these two species within the Campanulaceae. The loss of $a c c D$ fits with evidence for this gene having been transferred to the nuclear genome in the Campanulaceae [30]. The accD, rpl23 and infA genes have also been independently lost from the plastid genome in multiple other angiosperm lineages [31-33].

Several gene duplications have also occurred, which appear unique to C. americanum, though similar in pattern to those observed in T. caeruleum [29]. There has been a 300 bp partial duplication of $p s b B$ and a partial duplication of the beginning of rrn16 upstream of the full $r r n 16$ gene. The $n d h F$ gene has experienced multiple partial duplications including two identical $100 \mathrm{bp}$ duplications as well as a separate $70 \mathrm{bp}$ duplication. Several tRNAs were also duplicated, with two tandem copies of trnM-CAU, two copies of trnS-GCU, and three copies of both trnfM-CAU (two in tandem) and trnL-CAA spread throughout the genome. Duplications of tRNAs were also found in T. caeruleum where trnI-CAU is present in two copies [29].

One plastid gene, $p s b T$, has undergone multiple duplication events, leading to three full-length copies in the $C$. americanum genome. One of these copies is highly conserved and retains the ancestral amino acid sequence when compared to T. caeruleum, $H$. annuus, and $N$. tabacum, while the other two copies have accumulated multiple amino acid changes. Again, a similar phenomenon was observed in T. caeruleum, where a different photosystem II gene, $p s b$ J, is present in three copies [29]. 
Interspecific divergence in cpDNA sequence

The $\mathrm{dN} / \mathrm{dS}$ ratio varied widely across $C$. americanum's plastid genes, suggesting these genes are experiencing different selective regimes (Figure 1, Table 2). The photosynthesis genes exhibited evidence of strong purifying selection, as indicated by their low $\mathrm{dN} / \mathrm{dS}$ ratios (Table 2), while $y c f 1, y c f 2$, clpP, and the small subunit ribosomal protein genes had elevated $\mathrm{dN} / \mathrm{d} S$ ratios close to or above one, suggesting the possibility of relaxed purifying selection, positive selection, or a mixture of both (Table 2, Figure 1). These genes also varied in the extent to which changes in $\mathrm{dN}$ or $\mathrm{dS}$ led to the elevated $\mathrm{dN} / \mathrm{dS}$ ratios, suggesting that the selective regime leading to the elevated ratios may not be consistent across genes. Relative to other genes, $y c f 1$ and $y c f 2$ exhibited both an elevated $\mathrm{dN}$ and $\mathrm{dS}$, while the small subunit ribosomal protein genes had only an elevated $\mathrm{dN}$ (Figure 1) The clpP gene exhibited a moderate increase in $\mathrm{dN}$ as well as a greatly reduced
$\mathrm{dS}$ (Figure 1). The estimated $\mathrm{d} S$ of zero for $\operatorname{clpP}$ is likely to be a statistical anomaly due to the short sequence length providing a limited number of sites at which synonymous substitutions can occur. In addition, the branch leading to $T$. caeruleum and $C$. americanum exhibited an accelerated substitution rate and a $\mathrm{dN} / \mathrm{dS}$ ratio greater than one for clpP (Additional file 5: Table S2). Therefore, the high $\mathrm{dN} / \mathrm{dS}$ ratio found for $\operatorname{clpP}$ in $C$. americanum does not appear to be an artifact of the low estimated $\mathrm{dS}$ for this gene.

The high $\mathrm{dN} / \mathrm{dS}$ ratio suggests that positive selection may be acting on $c l p P$. Further support for positive selection was identified when comparing branch lengths inferred from $c l p P$ intronic and exonic sequence. The exonic tree showed a greatly increased branch length $(>7 x)$ on the branch leading to $C$. americanum and $T$. caeruleum relative to the intronic tree (Figure 2). In contrast, the branch length on the branches leading to $H$.

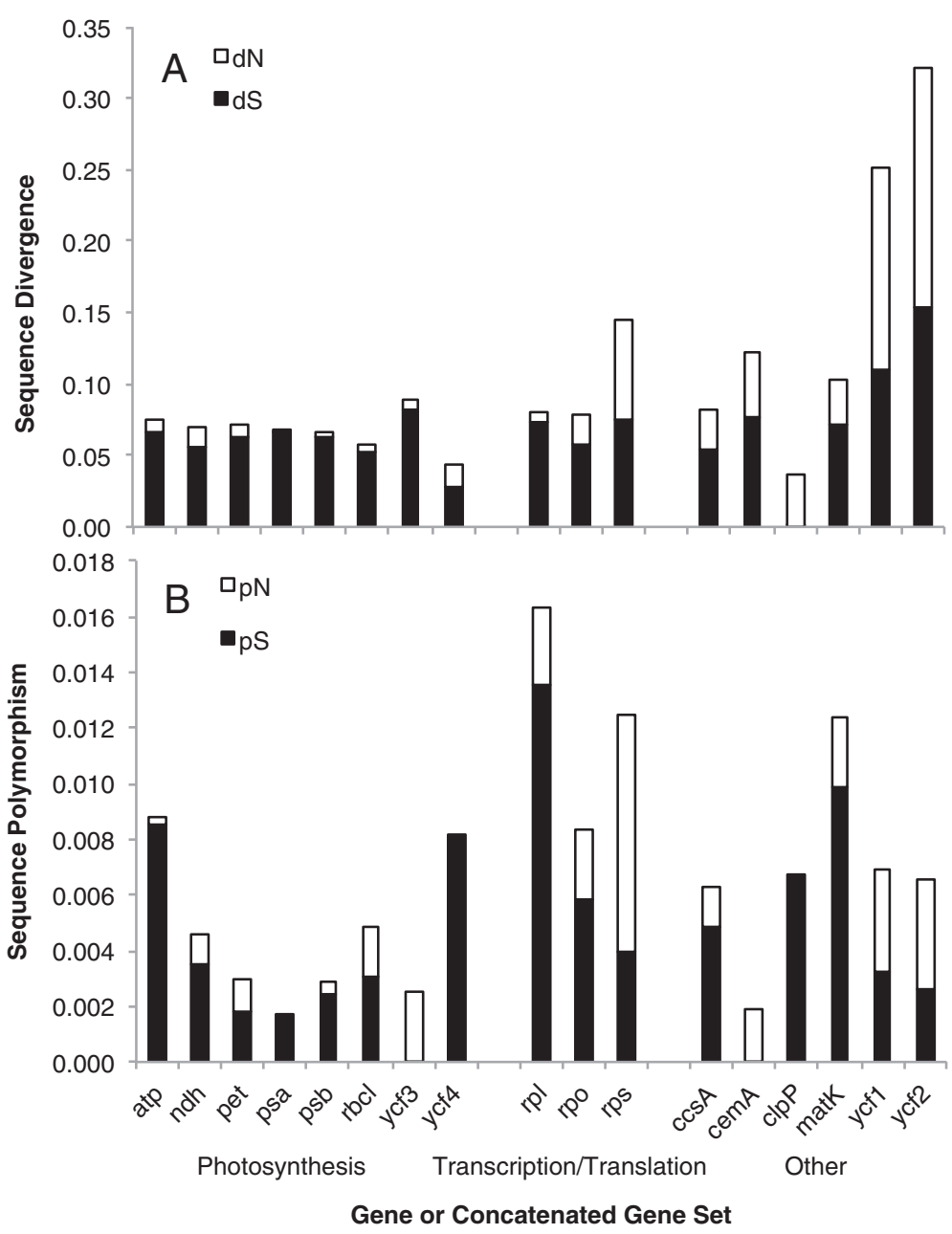

Figure 1 Sequence divergence (A) and polymorphism (B) for Campanulastrum americanum protein coding plastid genes. Sequence divergence and polymorphism as estimated by the number of substitutions per site in the terminal branch leading to $C$. americanum or within the species, respectively. Black and white bars indicate substitutions at synonymous and non-synonymous sites, respectively. 
Table 2 Sequence divergence and polymorphism values for Campanulastrum americanum protein coding plastid genes

\begin{tabular}{|c|c|c|c|c|}
\hline Gene & $\mathrm{dN} / \mathrm{dS}$ & $\mathrm{pN} / \mathrm{pS}$ & \# Polymorphisms & Gene Length \\
\hline \multicolumn{5}{|c|}{ Photosynthesis } \\
\hline atp & 0.131 & 0.031 & 11 & 4929 \\
\hline ndh & 0.248 & 0.324 & 17 & 10263 \\
\hline pet & 0.137 & 0.649 & 3 & 2289 \\
\hline psa & 0.031 & 0.000 & 2 & 4929 \\
\hline psb & 0.079 & 0.173 & 6 & 6360 \\
\hline $\mathrm{rbcl}$ & 0.102 & 0.605 & 3 & 1425 \\
\hline$y c f 3$ & 0.093 & NA & 1 & 504 \\
\hline$y c f 4$ & 0.605 & 0.000 & 1 & 552 \\
\hline \multicolumn{5}{|c|}{ Transcription and Translation } \\
\hline$r p l$ & 0.326 & 0.204 & 14 & 2757 \\
\hline rpo & 0.354 & 0.428 & 33 & 10230 \\
\hline rps & 0.915 & 2.135 & 36 & 4788 \\
\hline \multicolumn{5}{|l|}{ Other } \\
\hline $\operatorname{ccs} A$ & 0.509 & 0.290 & 2 & 918 \\
\hline cemA & 0.578 & NA & 1 & 684 \\
\hline$c l p P$ & $5.412^{* a}$ & 0.000 & 1 & 555 \\
\hline matk & 0.406 & 0.257 & 6 & 1491 \\
\hline$y c f 1$ & 1.293 & 1.144 & 11 & 3042 \\
\hline$y c f 2$ & 1.086 & 1.528 & 26 & 7137 \\
\hline All Genes & $0.430^{\mathbf{b}}$ & 0.518 & & \\
\hline
\end{tabular}

*Indicates significance before Bonferroni correction $(p<0.05)$. a: $d N / d S$ ratio for $c l p P$ was estimated by calculating $\mathrm{dN} / \mathrm{dS}$ as if there had been one synonymous SNP. b: mean dN/dS ratio was calculated without including clpP. $\mathrm{NA}$ : $\mathrm{pN} / \mathrm{pS}$ ratio was inestimable due to $\mathrm{pS}$ being zero. annuus and $N$. tabacum were shorter in the exonic tree relative to the intronic tree. These results are similar to those found in the tribe Sileneae (Caryophyllaceae), where evidence for positive selection on $\operatorname{clp} P$ was also observed when comparing intron and exon tree branch lengths [6]. The increased length and high $\mathrm{dN} / \mathrm{dS}$ ratio (1.23) found for the branch leading to $C$. americanum and $T$. caeruleum suggest that altered selection was likely acting on $c l p P$ prior to the split of these two species (Additional file 5: Table S2).

\section{Intraspecific polymorphism in cpDNA sequence}

We detected a total of 174 high confidence SNPs in $62853 \mathrm{bp}$ of total protein coding sequence from the $C$. americanum plastid genome. As with divergence, the $\mathrm{pN} / \mathrm{pS}$ ratio also varied strongly across plastid genes, suggesting that they are continuing to experience differing selective regimes at the within-species level (Figure 1, Table 2). Similar to the divergence results, the photosynthetic genes appear to be under purifying selection, while $y c f 1, y c f 2$, and the small subunit ribosomal genes had signatures of relaxed purifying or positive selection as evidenced by their elevated $\mathrm{pN} / \mathrm{pS}$ ratios with values greater than one (Table 2, Figure 1). The elevated $\mathrm{pN} / \mathrm{pS}$ ratios for these genes were primarily due to a higher $\mathrm{pN}$, with the small subunit ribosomal genes in particular having a $\mathrm{pN}$ that is at least twice as high as for any other single gene or concatenation (Figure 1). On the other hand, $c l p P$ had a $\mathrm{pN} / \mathrm{pS}$ ratio of zero, but that is based on only a single identified SNP in C. americanum (Figure 1, Table 2).

The patterns of polymorphism also suggested the existence of structural variation in the plastid genome within C. americanum. The initial polymorphism data indicated

\section{A: Intronic}

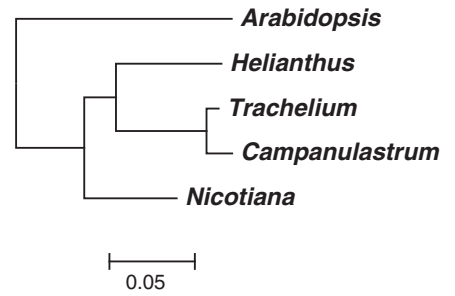

B: Exonic

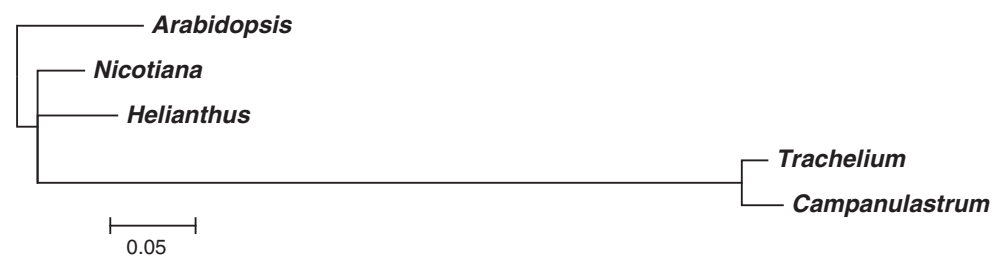

Figure 2 Trees for clpP intronic (A) and exonic (B) sequence. Trees with maximum likelihood branch length estimates using Arabidopsis thaliana as an outgroup. 
multiple non-synonymous SNPs within the first exon of clpP. Further examination of the pooled sequence data found evidence for a duplication of the first exon of $c l p P$ that did not appear to be present in the single population plastid assembly. Primers were then designed to amplify the first exon from either the full copy or duplication of clpP. The full copy first exon was amplified in all four populations used for sequencing the plastid genome (VA, $\mathrm{AL}, \mathrm{OH}$, and $\mathrm{MN}$ ), while the duplication was only amplified in $\mathrm{AL}, \mathrm{OH}$, and $\mathrm{MN}$, indicating the duplication does not exist in the VA population. These findings suggest the duplication event occurred since the divergence of the $C$. americanum populations. Sequencing and alignment of the partial duplication and full copy of $\operatorname{clpP}$ (deposited in Dryad [24]) recovered the nonsynonymous SNPs found in the initial polymorphism data, indicating they were artifacts caused by mapping the partial duplication to the full VA $\operatorname{clpP}$ copy.

\section{Polymorphism and divergence}

Overall the $\mathrm{dN} / \mathrm{dS}$ and $\mathrm{pN} / \mathrm{pS}$ ratios are correlated across C. americanum's plastid genes (Figure 3), suggesting that similar selective pressures are acting on the same genes across multiple time scales. The $\mathrm{dN} / \mathrm{dS}$ ratios on the unrooted branch connecting C. americanum and T. caeruleum to $H$. annuus and $N$. tabacum are also correlated with $C$. americanum's $\mathrm{dN} / \mathrm{dS}$ ratios $\left(\mathrm{R}^{2}=0.88, \mathrm{p}<0.001\right)$, further supporting similar selective pressures acting across time scales (Additional file 5: Table S2). While clpP seemed to deviate from this general pattern in that it showed a strongly elevated $\mathrm{dN} / \mathrm{dS}$ ratio but a $\mathrm{pN} / \mathrm{pS}$ ratio of zero, there is limited confidence in this estimate due to the short sequence length of $c l p P$ and the ratio being based only upon a single synonymous SNP.

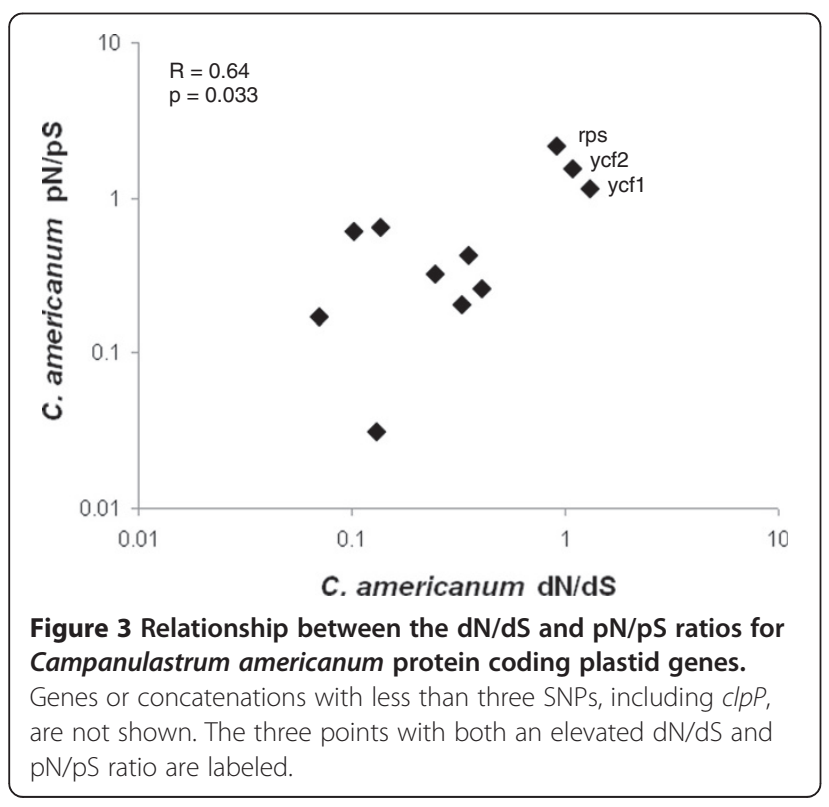

In general, the $\mathrm{M}-\mathrm{K}$ tests found no significant difference between the number of non-synonymous and synonymous SNPs when comparing the polymorphism and divergence data. The one exception was the set of the small subunit ribosomal proteins when using either $H$. annuus or N. tabacum as an outgroup. These analyses had a significant difference before, but not after, Bonferroni correction. In both of these comparisons, there was evidence for purifying selection, as the divergence among species had a lower ratio of non-synonymous to synonymous changes than the polymorphism within $C$. americanum. When using $T$. caeruleum as an outgroup, however, there was no longer a significant difference between the polymorphism and divergence SNP ratios for the small subunit ribosomal proteins.

\section{Discussion}

Previous studies have found the Campanulaceae sensu lato to have relatively unstable plastid genomes characterized by a high frequency of inversions, the presence of repetitive regions, as well as gene duplications [13,14,29]. Fitting these earlier findings, assembly and annotation of $C$. americanum's plastid genome revealed the presence of a number of repetitive regions as well as gene duplications. Further evidence for instability is suggested by a variable partial duplication of $c l p P$ among populations of $C$. americanum.

While the photosynthetic genes exhibited evidence for strong purifying selection, elevated nucleotide substitution rates and $\mathrm{dN} / \mathrm{dS}$ ratios were found for $y c f 1, y c f 2$, $c l p P$, and the small subunit ribosomal genes in C. americanum. The $y c f 1$ gene was recently found to be involved in protein translocation [34], while $y c f 2$ is essential for cell viability but of unknown function [35], and $c l p P$ codes for a protease subunit. The PAML analyses used average $\mathrm{dN} / \mathrm{dS}$ across the entire gene (or gene concatenation), making this a conservative test for positive selection (dN/dS significantly greater than 1 ). If only a subset of codons within a gene/concatenation were under positive selection, the analyses used would have been unlikely to detect this signature. Accordingly, it is possible that some of the genes that exhibited evidence of purifying selection may have had positive selection at a subset of sites. At the same time, the genes with elevated average $\mathrm{dN} / \mathrm{dS}$ ratios may have even higher $\mathrm{dN} / \mathrm{dS}$ ratios at specific sites.

These genes with an elevated dN/dS ratio also differed in whether this was due to underlying changes in $\mathrm{dN}$ or $\mathrm{dS}$, suggesting that the selective regime leading to the elevated ratios may not be consistent across genes. As synonymous substitutions are neutral, changes in dS are likely to reflect changes in the underlying mutation rate, potentially due to problems with DNA repair, whereas rates of non-synonymous substitutions are impacted not 
only by the underlying mutation rate, but also selection. Therefore changes in $\mathrm{dN}$ can also give insight into changes in selection. Relative to other genes, $y c f 1$ and $y c f 2$ exhibit both an elevated $\mathrm{dN}$ and $\mathrm{dS}$, though the increase in $\mathrm{dN}$ was greater than $\mathrm{dS}(2.5 \times$ and $1.5 \times$ higher respectively), suggesting that the underlying mutation rate, as well as potentially the selective regime, has been altered in the these genes. In contrast, the small subunit ribosomal protein genes had only an elevated $\mathrm{dN}$ (Figure 1), strongly suggesting a change in selective regime, and not underlying mutation rate has led to the elevated $\mathrm{dN} / \mathrm{dS}$ ratio in these genes. The $\operatorname{clpP}$ gene exhibits a moderate increase in $\mathrm{dN}$ as well as a greatly reduced dS. However, the uncertainties regarding the estimate of $\mathrm{dS}$ for this gene make it difficult to come to any conclusions regarding the underlying causes of the elevated $\mathrm{dN} / \mathrm{dS}$ ratio.

A similar set of plastid genes (including $y c f 1, y c f 2, c l p P$, and ribosomal protein genes) have increased nucleotide substitution rates and elevated $\mathrm{dN} / \mathrm{dS}$ ratios in other taxa [3], including species within the tribe Sileneae $[6,8,9]$, the genus Oenothera [6,7], and the Geraniaceae $[4,10]$. Increased nucleotide substitution rates have also been associated with increased structural variability [3], similar to our findings in C. americanum. These similarities suggest the possibility of a common evolutionary mechanism, whether adaptive or non-adaptive [9]. Our results suggest that this mechanism is continuing to operate at very recent time scales because we detect similar accelerated plastid evolution at the within-species level.

Almost all of the M-K tests were non-significant, indicating not only a lack of support for positive selection acting on the genes with an elevated $\mathrm{dN} / \mathrm{dS}$ ratio, but also no support for purifying selection acting on the genes with a low $\mathrm{dN} / \mathrm{dS}$ ratio. This lack of significance is probably due to the low power of the M-K tests we used, as a result of two factors. First, for several of the plastid genes/concatenations there are low levels of polymorphism (Table 2), which restricts the power of the M-K test. Second, one of the four C. americanum populations sequenced for this study (VA) has a plastid genome that is highly divergent from the other three. Therefore, most of the polymorphisms observed in C. americanum are likely fixed within populations and old enough that they have been subject to significant selection. The M-K test compares neutrally arising variation (within species polymorphism) to fixed differences after selection has acted (between species divergence) [12]. If selection has acted on within species polymorphism, this will reduce the power of the $\mathrm{M}-\mathrm{K}$ test to detect a significant difference between the polymorphism and divergence data. Therefore, when there is substantial intraspecific divergence, such as in C. americanum, the nature of the polymorphism data makes it difficult to definitively distinguish between the contributions of positive selection and relaxed purifying selection to the increased nucleotide substitution rates and $\mathrm{dN} / \mathrm{dS}$ ratios observed in some plastid genes. Future studies using increased sampling could allow for more sensitive tests for positive selection. For example, the recent sequencing of dozens of chloroplast genomes within the Campanulaceae sensu lato [14] raises the future possibility of using phylogenetic tests to look for site-specific positive selection.

Accelerated plastid evolution may be an important contributor to the development of reproductive isolation and subsequent speciation. The nuclear and plastid genome are likely to be co-evolved as they must interact closely to carry out essential functions, such as photosynthesis [36]. Increased nucleotide substitution rates, altered selective regimes, and increased structural variation have the potential to lead to rapid local co-evolution of these genomes, leading to an increased likelihood for cytonuclear genetic incompatibilities when crossing between populations. Cytonuclear incompatibilities are proposed to be among the first genetic incompatibilities to arise [37,38] and are increasingly thought to play an important role in the speciation process as they have been implicated in contributing to reproductive isolation in plants, yeast, and animals [39-42].

Strong reproductive isolation is found between populations of $C$. americanum, and the asymmetrical pattern of this breakdown along with observations of chlorosis and variegation (Figure 4) suggest cytonuclear incompatibilities contribute to this isolation $[15,43]$. Positive and or relaxed purifying selection on $y c f 1, y c f 2, c l p P$ and the small subunit ribosomal genes, as well as the general instability of the plastid genome, may contribute to cytonuclear

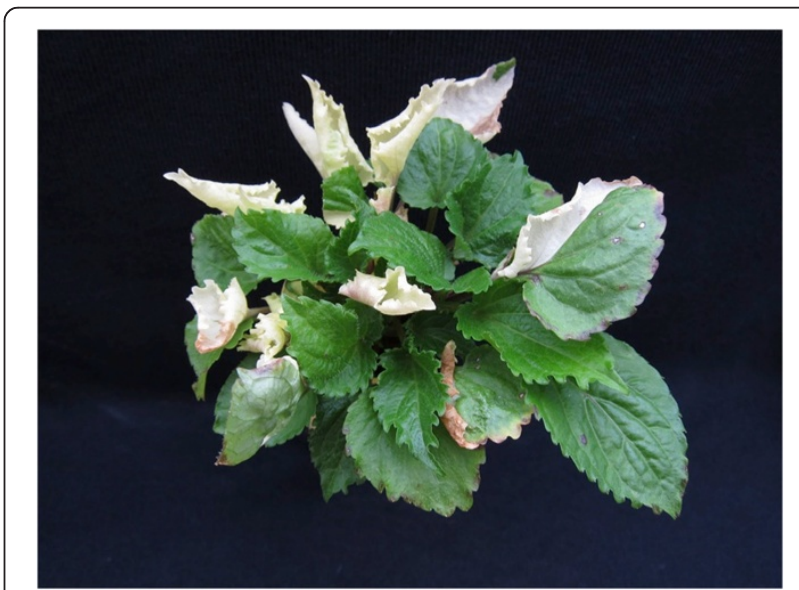

Figure 4 Intraspecific first-generation (F1) hybrid of Campanulastrum americanum showing variegation. This variegation is representative of what is found when crossing between populations with high levels of genetic divergence, such as the divergence between Virginia and remaining three populations used in this study. 
incompatibility and reproductive isolation in $C$. americanum. The small subunit ribosomal genes in particular are interesting candidates for intraspecific cytonuclear incompatibilities due to their highly elevated level of $\mathrm{pN}$ and the fact that nuclear-encoded subunits of organelle ribosomes have been found to exhibit evidence of compensatory substitutions in response to rapid evolution of organelle genomes $[44,45]$.

Similar to $C$. americanum, other independent lineages of angiosperms have increases in nucleotide substitution rate and elevated $\mathrm{dN} / \mathrm{dS}$ for a subset of plastid genes $[1,3]$. Could accelerated plastid genome evolution also contribute to cytonuclear incompatibility and reproductive isolation in these lineages? Cytonuclear incompatibilities are known from interspecific crosses in Oenothera [reviewed in [46]] and in Pelargonium [47,48], both of which exhibit similar patterns of accelerated plastid evolution. However, cytonuclear incompatibilities and reproductive isolation are rarely examined at the intraspecific level. Further work in examining the relationship between accelerated plastid evolution, cytonuclear incompatibility, and reproductive isolation at the intraspecific level would allow for a more general conclusion as to whether accelerated evolution and positive selection on plastid genes could help drive the early stages of the speciation process.

\section{Conclusions}

We found increased nucleotide substitution rates when examining intraspecific polymorphism in the plastid genome of $C$. americanum. In addition, there was a significant correlation between the $\mathrm{dN} / \mathrm{dS}$ and $\mathrm{pN} / \mathrm{pS}$ ratios across plastid genes. These results provide evidence that mechanisms leading to increased nucleotide substitution rates in the plastid genome are continuing to operate at recent evolutionary timescales and may, therefore, be contributing to the early stages of the speciation process through the development of intraspecific cytonuclear incompatibilities and reproductive isolation.

\section{Availability of supporting data}

The data sets supporting the results of this article are available in the Dryad repository, [doi:10.5061/ dryad.d143r, http://datadryad.org/resource/doi:10.5061/ dryad.d143r].

\section{Additional files}

Additional file 1: Sequence of clpP for Trachelium caeruleum with re-annotated intron/exon boundaries. Exons in capital letters and introns in lowercase.

Additional file 2: Table S1. Designation of which individual genes were included in concatenations. Also includes list of genes analyzed individually. NA: genes excluded from analysis, see text for details.
Additional file 3: Perl script used for extracting intraspecific SNPs. Additional file 4: Perl script used for extracting interspecific SNPs.

Additional file 5: Table S2. dN/dS ratios for all four species used in the divergence analyses. $\mathrm{dN} / \mathrm{dS}$ ratios from the codeml analyses for the terminal branches leading to each species as well as for the internal branch leading to the common ancestor of T. caeruleum and C. americanum. *: N. tabacum is the outgroup in the analysis, and therefore the reported values are a combination of the terminal branch and the divergence on the internal branch leading to the Asterales. a: dN/dS ratio for clpP was estimated by calculating $\mathrm{dN} / \mathrm{dS}$ as if there had been one synonymous SNP.

\section{Competing interests}

The authors declare that they have no competing interests.

\section{Authors' contributions}

KBB-K participated in the design of the study, DNA isolation, analysis and interpretation of the sequence data, and in drafting the manuscript. DBS participated in the design of the study, DNA isolation, analysis and interpretation of the sequence data, and in drafting the manuscript. LFG participated in design of the study, interpretation of the data, and drafting the manuscript. All authors read and approved the final manuscript.

\section{Acknowledgements}

We thank Doug Taylor for his assistance in planning the project, John Chuckalovcak for his 454 sequencing efforts, and Martin Wu for his support in carrying out the sequencing. We also thank Janis Antonovics and three anonymous reviewers for constructive feedback on earlier drafts of this manuscript. This work was supported by the National Science Foundation (DEB-0922214) and the ARCS Foundation. This article was published in part thanks to funds provided by the University of Virginia Library Open Access Fund.

\section{Author details}

${ }^{1}$ Department of Biology, University of Virginia, P.O. Box 400328 ,

Charlottesville, VA 22904-4328, USA. ²Department of Biology, Colorado State University, Fort Collins, CO 80523, USA.

Received: 5 July 2014 Accepted: 11 December 2014

Published online: 24 December 2014

\section{References}

1. Jansen R, Ruhlman T: Plastid genomes of seed plants. In Genomics of Chloroplasts and Mitochondria, Volume 35. Edited by Bock R, Knoop V. Netherlands: pringer; 2012:103-126.

2. Drouin G, Daoud H, Xia J: Relative rates of synonymous substitutions in the mitochondrial, chloroplast and nuclear genomes of seed plants. $\mathrm{Mol}$ Phylogenet Evol 2008, 49(3):827-831.

3. Jansen RK, Cai Z, Raubeson LA, Daniell H, Depamphilis CW, Leebens-Mack J, Muller KF, Guisinger-Bellian M, Haberle RC, Hansen AK, Chumley TW, Lee SB, Peery R, McNeal JR, Kuehl JV, Boore JL: Analysis of 81 genes from 64 plastid genomes resolves relationships in angiosperms and identifies genome-scale evolutionary patterns. Proc Natl Acad Sci U S A 2007, 104(49):19369-19374.

4. Guisinger MM, Kuehl JV, Boore JL, Jansen RK: Genome-wide analyses of Geraniaceae plastid DNA reveal unprecedented patterns of increased nucleotide substitutions. Proc Natl Acad Sci U S A 2008, 105(47):18424-18429.

5. Khakhlova O, Bock R: Elimination of deleterious mutations in plastid genomes by gene conversion. Plant J 2006, 46(1):85-94.

6. Erixon P, Oxelman B: Whole-gene positive selection, elevated synonymous substitution rates, duplication, and indel evolution of the chloroplast clpP1 gene. PLOS ONE 2008, 3(1):e1386.

7. Greiner S, Wang X, Herrmann RG, Rauwolf U, Mayer K, Haberer G, Meurer J: The complete nucleotide sequences of the 5 genetically distinct plastid genomes of Oenothera, subsection Oenothera: II. A microevolutionary view using bioinformatics and formal genetic data. Mol Biol Evol 2008 25(9):2019-2030.

8. Sloan DB, Alverson AJ, Wu M, Palmer JD, Taylor DR: Recent acceleration of plastid sequence and structural evolution coincides with extreme mitochondrial divergence in the angiosperm genus Silene. Genome Biol Evol 2012, 4(3):294-306. 
9. Sloan DB, Triant DA, Forrester NJ, Bergner LM, Wu M, Taylor DR: A recurring syndrome of accelerated plastid genome evolution in the angiosperm tribe Sileneae (Caryophyllaceae). Mol Phylogenet Evol 2014, 72:82-89.

10. Weng ML, Ruhlman TA, Gibby M, Jansen RK: Phylogeny, rate variation, and genome size evolution of Pelargonium (Geraniaceae). Mol Phylogenet Evol 2012, 64(3):654-670.

11. Hudson RR, Kreitman M, Aguade M: A test of neutral molecular evolution based on nucleotide data. Genetics 1987, 116(1):153-159.

12. McDonald JH, Kreitman M: Adaptive protein evolution at the Adh locus in Drosophila. Nature 1991, 351(6328):652-654.

13. Cosner ME, Raubeson LA, Jansen RK: Chloroplast DNA rearrangements in Campanulaceae: phylogenetic utility of highly rearranged genomes. $B M C$ Evol Biol 2004, 4:27

14. Knox EB: The dynamic history of plastid genomes in the Campanulaceae sensu lato is unique among angiosperms. Proc Natl Acad Sci U S A 2014, 111(30):11097-11102.

15. Galloway LF, Etterson JR: Population differentiation and hybrid success in Campanula americana: geography and genome size. J Evol Biol 2005, 18(1):81-89.

16. Galloway LF, Etterson JR, Hamrick JL: Outcrossing rate and inbreeding depression in the herbaceous autotetraploid, Campanula americana. Heredity 2003, 90(4):308-315.

17. Corriveau JL, Coleman AW: Rapid screening method to detect potential biparental inheritance of plastid DNA and results for over 200 angiosperm species. Am J Bot 1988, 75(10):1443-1458.

18. Zhang Q, Liu Y, Sodmergen: Examination of the cytoplasmic DNA in male reproductive cells to determine the potential for cytoplasmic inheritance in 295 angiosperm species. Plant Cell Physiol 2003, 44(9):941-951.

19. Palmer JD: Isolation and structural-analysis of chloroplast DNA. Methods Enzymol 1986, 118:167-186.

20. Jansen RK, Raubeson LA, Boore JL, DePamphilis CW, Chumley TW, Haberle RC, Wyman SK, Alverson AJ, Peery R, Herman SJ, Fourcade HM, Kuehl JV, McNeal JR, Leebens-Mack J, Cui L: Methods for obtaining and analyzing whole chloroplast genome sequences. Method Enzymol 2005, 395:348-384.

21. Gordon D, Abajian C, Green P: Consed: A graphical tool for sequence finishing. Genome Res 1998, 8(3):195-202.

22. Wyman SK, Jansen RK, Boore JL: Automatic annotation of organellar genomes with DOGMA. Bioinformatics 2004, 20(17):3252-3255.

23. Edgar RC: MUSCLE: multiple sequence alignment with high accuracy and high throughput. Nucleic Acids Res 2004, 32(5):1792-1797.

24. Barnard-Kubow KB, Sloan DB, Galloway LF (2014) Data from: Correlation between sequence divergence and polymorphism reveals similar evolutionary mechanisms acting across multiple timescales in a rapidly evolving plastid genome. Dryad Digit Repository. 10.5061/dryad.d143r

25. Yang ZH: PAML 4: Phylogenetic analysis by maximum likelihood. Mol Biol Evol 2007, 24(8):1586-1591.

26. Yang ZH: Likelihood ratio tests for detecting positive selection and application to primate lysozyme evolution. Mol Biol Evol 1998, 15(5):568-573.

27. Darriba D, Taboada GL, Doallo R, Posada D: jModelTest 2: more models, new heuristics and parallel computing. Nat Methods 2012, 9(8):772.

28. Guindon S, Gascuel O: A simple, fast, and accurate algorithm to estimate large phylogenies by maximum likelihood. Syst Biol 2003, 52(5):696-704.

29. Haberle RC, Fourcade HM, Boore $\mathrm{JL}$, Jansen RK: Extensive rearrangements in the chloroplast genome of Trachelium caeruleum are associated with repeats and tRNA genes. J Mol Evol 2008, 66(4):350-361.

30. Rousseau-Gueutin M, Huang X, Higginson E, Ayliffe M, Day A, Timmis JN: Potential functional replacement of the plastidic acetyl-CoA carboxylase subunit $(a c c D)$ gene by recent transfers to the nucleus in some angiosperm lineages. Plant Physiol 2013, 161(4):1918-1929.

31. Millen RS, Olmstead RG, Adams KL, Palmer JD, Lao NT, Heggie L, Kavanagh TA, Hibberd JM, Giray JC, Morden CW, Calie PJ, Jermiin LS, Wolfe KH: Many parallel losses of infA from chloroplast DNA during angiosperm evolution with multiple independent transfers to the nucleus. Plant Cell 2001, 13(3):645-658.

32. Zurawski G, Clegg MT: Evolution of higher-plant chloroplast DNA-encoded genes: implications for structure-function and phylogenetic studies. Annu Rev Plant Physiol Plant Mol Biol 1987, 38:391-418.

33. Delannoy E, Fujii S, des Francs-Small CC, Brundrett M, Small I: Rampant gene loss in the underground orchid Rhizanthella gardneri highlights evolutionary constraints on plastid genomes. Mol Biol Evol 2011, 28(7):2077-2086.

34. Kikuchi S, Bedard J, Hirano M, Hirabayashi Y, Oishi M, Imai M, Takase M, Ide T, Nakai M: Uncovering the protein translocon at the chloroplast inner envelope membrane. Science 2013, 339(6119):571-574.

35. Drescher A, Ruf S, Calsa T, Carrer H, Bock R: The two largest chloroplast genome-encoded open reading frames of higher plants are essential genes. Plant J 2000, 22(2):97-104

36. Rand DM, Haney RA, Fry AJ: Cytonuclear coevolution: the genomics of cooperation. Trends Ecol Evol 2004, 19(12):645-653.

37. Fishman L, Willis $\mathrm{JH}$ : A cytonuclear incompatibility causes anther sterility in Mimulus hybrids. Evolution 2006, 60(7):1372-1381.

38. Levin DA: The cytoplasmic factor in plant speciation. Syst Bot 2003, 28(1):5-11.

39. Chou JY, Leu JY: Speciation through cytonuclear incompatibility: Insights from yeast and implications for higher eukaryotes. Bioessays 2010, 32(5):401-411.

40. Ellison CK, Burton RS: Interpopulation hybrid breakdown maps to the mitochondrial genome. Evolution 2008, 62(3):631-638.

41. Leppala J, Savolainen O: Nuclear-cytoplasmic interactions reduce male fertility in hybrids of Arabidopsis lyrata subspecies. Evolution 2011, 65(10):2959-2972.

42. Sambatti JBM, Ortiz-Barrientos D, Baack EJ, Rieseberg LH: Ecological selection maintains cytonuclear incompatibilities in hybridizing sunflowers. Ecol Lett 2008, 11(10):1082-1091.

43. Etterson JR, Keller SR, Galloway LF: Epistatic and cytonuclear interactions govern outbreeding depression in the autotetraploid Campanulastrum americanum. Evolution 2007, 61(11):2671-2683.

44. Barreto FS, Burton RS: Evidence for compensatory evolution of ribosomal proteins in response to rapid divergence of mitochondrial rRNA. Mol Biol Evol 2013, 30(2):310-314.

45. Sloan DB, Triant DA, Wu M, Taylor DR: Cytonuclear interactions and relaxed selection accelerate sequence evolution in organelle ribosomes. Mol Biol Evol 2014, 31(3):673-682.

46. Greiner S, Rauwolf U, Meurer J, Herrmann RG: The role of plastids in plant speciation. Mol Ecol 2011, 20(4):671-691.

47. Metzlaf M, Pohlheim F, Börner T, Hagemann R: Hybrid variegation in the genus Pelargonium. Curr Genet 1982, 5(3):245-249.

48. Weihe A, Apitz J, Pohlheim F, Salinas-Hartwig A, Borner T: Biparental inheritance of plastidial and mitochondrial DNA and hybrid variegation in Pelargonium. Mol Genet Genomics 2009, 282(6):587-593.

\section{Submit your next manuscript to BioMed Central and take full advantage of:}

- Convenient online submission

- Thorough peer review

- No space constraints or color figure charges

- Immediate publication on acceptance

- Inclusion in PubMed, CAS, Scopus and Google Scholar

- Research which is freely available for redistribution 